\title{
Sero-Prevalence of Measles in Southern Darfur State, Sudan
}

\author{
Hassan Hussein Musa ${ }^{1,2, *}$, Taha Hussin Musa ${ }^{2,3}$, Rehab I Kambo ${ }^{4}$, Abdelkareem A Ahmed ${ }^{1,5}$ and Idriss Husseiiin Musa ${ }^{6}$ \\ ${ }^{1}$ Biomedical Research Institute, Darfur College, Nyala, Sudan \\ ${ }^{2}$ Department of Medical Microbiology, Faculty of Medical Laboratory Sciences, University of Khartoum, Sudan \\ ${ }^{3}$ Department Epidemiology and Health Statistics, School of Public Health, Southeast University, Nanjing, China \\ ${ }^{4}$ World Health Organization, South Darfur Sub-Office, Nyala, Sudan \\ ${ }^{5}$ Department of Physiology and Biochemistry, Faculty of Veterinary Sciences, University of Nyala, Sudan \\ ${ }^{6}$ School of Medicine, Darfur College, Nyala, Sudan
}

*Corresponding author: Hassan Hussein Musa, Biomedical Research Institute, Darfur College, Nyala, Sudan, E-mail: hassanhm@uofk.edu

Received: 30 Jun, 2020 | Accepted: 21 Jul, 2020 | Published: 27 Jul, 2020

Citation: Musa HH, Musa TH, Kambo RI, Ahmed AA, Musa IH (2020) Sero-Prevalence of Measles in Southern Darfur State, Sudan. J Emerg Dis Virol 5(2): dx.doi.org/10.16966/2473-1846.154

Copyright: (C) 2020 Musa HH, et al. This is an open-access article distributed under the terms of the Creative Commons Attribution License, which permits unrestricted use, distribution, and reproduction in any medium, provided the original author and source are credited.

\begin{abstract}
Background: Measles is a highly contagious acute viral disease; it remains among the top causes of death in young children globally. The purpose is to study the serology and clinical profile of measles in Southern Darfur State, Sudan.

Methods: Cross-sectional laboratory-based study was conducted (2011-2015) in six health zones in Southern Darfur State, Sudan. A total of 511 sera were obtained from measles patients during the surveillance, and the sera were screened for IgM antibodies using ELISA.

Results: A $43.4 \%$ of cases was males, and $56.6 \%$ were females, the commonly affected age was $1-4$ years in both sexes. The sero-prevalence of measles lab-confirmed cases was $48.5 \%$, most cases were reported in Nyala and Rahad Elberdi health zones. The suspected measles cases were increased from February to June and decreased from July to December. Measles lab-confirmed cases were higher compared with Epi-linked and Measles compatible cases in different health zone. The characteristic of measles clinical symptoms was fever $100 \%$, cough $100 \%$, maculopapular rash $100 \%$, running nose $22.1 \%$, conjunctivitis $67.3 \%$, arthritis $25.8 \%$, and lymphadenopathy $6.7 \%$. However, $25.0 \%$ of cases had severe measles complication, $98.2 \%$ were recovered during the hospitalization, and $1.8 \%$ resulted in death. A $21.3 \%$ of cases were vaccinated, and $48.53 \%$ had measles IgM positive antibody. The trend of measles shown clinically significant differences in gender $\left(\chi^{2}=55.68, P<0.001\right)$, age year $\left(X^{2}=48.83\right.$, $\mathrm{P}<0.001)$ and presences of measles IgM antibody in the serum $\left(\chi^{2}=261.27, P<0.001\right)$.
\end{abstract}

Conclusion: The study reported a high percentage of measles IgM antibody in Southern Darfur State.

Keywords: Measles IgM antibody; Sero-prevalence; South Darfur; Sudan

\section{Introduction}

Measles is an acute, highly infectious viral disease. The disease symptoms start with a cough, fever, and a maculopapular rash that can lead to severe complications, including acute diarrhea, encephalitis, ear infection, blindness, inflammation of the brain, and pneumonia, followed by substantial morbidity mainly in a developing country $[1,2]$.

Despite the unique national childhood vaccination campaigns that have been successfully used to control measles morbidity and mortality over the past years, measles continues to be endemic in many developing countries. The ways for prevention and control of measles elimination are especially challenging to implement in East Africa, because of its limited infrastructure and political instability [3], in addition to the insufficient vaccination coverage, logistical problems related to cold chain maintenance, and civil wars. Therefore, measles remains a public health concern in developing areas $[4,5]$.
In developing areas of Africa and Asia countries, measles affects about 20 million people a year [6,7], and 95\% of measles death cases occur in developing countries with weak health infrastructures [2].

In the African region, where the measles vaccine was introduced in the 1970 s, the mortality was declined to $40 \%$ [8]. Recent studies indicated that measles-related death was decreased by $90 \%$ between 2000 and 2008 through the effective implementation of WHO and UNICEF-recommended control strategies [9]. A second dose of measles-containing vaccine given during supplemental immunization activities played a vital role in raising the population's immunity levels. However, routine vaccination coverage remains low, and health systems are still weak $[9,10]$. The previous study showed that $86.8 \%$ of children were positive for the anti-measles virus-specific IgM antibodies [11].

Recently more than 1600 suspected measles cases with 710 confirmed have been reported from 23 localities in 12 states of Sudan 
[2]. The latest study conducted by Musa et al. indicated an increase in measles cases in South Darfur state [12]. Furthermore, The Darfur region is considered the most affected state in Sudan [2]. In this study, we reported the serological findings and clinical profile of measles in Southern Darfur State, Sudan.

\section{Methods}

\section{Study area}

The study was conducted in Southern Darfur State, Sudan, the state covered an area of $127,300 \mathrm{~km}^{2}$ and occupied by approximately $4,069,300$ people, most are displaced people IDPs from the northern and western Darfur States. The state has six health zones, including Nyala, Iddel Fursan, Tulus, Buram, Rahad Elberdi, and Kass. Nyala city is the capital of the State.

\section{Study population}

The data in this study was obtained from the WHO sub-office Nyala. In total, 511 notified cases were eligible for inclusion during the measles surveillances from $1^{\text {st }}$ January 2011 to $31^{\text {st }}$ December 2015, from six health zone in Southern Darfur State, Sudan. The cases were admitted to local primary health care centers in Southern Darfur state. The data obtained includes demographic, vaccination status and clinical symptoms of suspected measles. The study was approved by the Ministry of Health, Southern Darfur State, Sudan.

\section{Measles IgM antibodies detection}

Blood samples were collected from all patients during the study period; blood samples were allowed to clot and then centrifuged at $3000 \mathrm{rpm}$ for 5 minutes. The sera were then harvested into clean, sterile bottles and stored at $-20^{\circ} \mathrm{C}$ before assay. The serological test was carried out by ELISA based on the World Health Organization guideline protocol [6]. Where define measles case surveillance as;

Suspected A case with signs and symptoms consistent with measles clinical criteria.

Laboratory confirmed: A suspected case that meets the laboratory criteria for measles case confirmation.

Epidemiologically linked: A suspected case that has not been adequately tested by laboratory and was in contact with a laboratoryconfirmed measles case 7-18 days before the onset of symptoms.

Clinically compatible: A suspected case that has not been adequately tested by laboratory and has not been epidemiologically linked to a confirmed measles case.

Discarded: A suspected case that was investigated and discarded, either through negative results of adequate laboratory testing for measles or by an epidemiologic link to a laboratory-confirmed case of another disease.

\section{Statistical Analysis}

The data from 2011 to 2015 were extracted and analyzed using SPSS (version 20.0; SPSS Inc., Chicago, IL). The frequency of cases was calculated using frequency analysis, cross-tabulation and chi-square tests. A P-value $<0.05$ was considered statistically significant.

\section{Results}

A total of 511 samples were clinically confirmed measles cases in six health zones; Nyala 297 (58.1\%), Iddel Fursan 15 (2.9\%), Tulus 10 (2.0\%), Buram 20 (3.9\%), Rahad Elberdi 152 (29.7\%), and Kass 17 (3.3\%).
Among studied cases, 222 (43.4\%) were males, and 289 (56.6\%) were females, their ages ranged from 1 to $15 \sim$ years. Cases aged less than five years old were most affected by measles compared with other aged groups (Figure 1).

The seasonality of suspected measles cases indicates that measles cases were increased during February, March, April, May, and June. Whereas, the measles cases were decreased in July, August, September, October, and December (Figure 2).

Measles lab-confirmed cases are high compared with Epi-linked and Measles compatible cases in different health zones (Figure 3). Measles positive and negative cases in different health zones are presented in figure 4.

Measles clinical symptoms were fever 511 (100\%), cough $511(100 \%)$, maculopapular rash 511 (100\%), running nose 113 (22.1\%), conjunctivitis 344 (67.3\%), arthritis 132 (25.8\%), and lymphadenopathy $34(6.7 \%)$. However, $128(25.0 \%)$ of measles cases displayed severe complications, and 502 (98.2\%) were recovered during the hospitalization, while the mortality rate was $9(1.8 \%)$ (Table1)

There were clinically significant differences in gender $\left(\chi^{2}=55.68\right.$, $\mathrm{P}<0.001)$, age year $\left(\chi^{2}=48.83, \mathrm{P}<0.001\right)$ and presences of antibody in the serum for measles IgM antibody $\left(\chi^{2}=261.27, \mathrm{P}<0.001\right)$ (Table 2$)$.

\section{Discussion}

Measles remains among the top causes of death in young children globally [6]. Due to its high infectious rates and the potential severity of complications, measles often constitutes a severe public health event entailing a vigorous response from public health departments and can involve multiple states and counties [13]. In Sudan, the measles was reported in Gedarif and Kassala States in December 2014. Recently, new cases were reported among internal displacement people in Northern Darfur (Jabel Amer, Sharaf Omra) [14]. The present study indicated that measles remained a public health concern in Southern Darfur state. Among measles cases, the percentage of females was higher than males, and most cases were reported in aged less than five years. Several epidemiological studies have shown that infection with measles occurred within the first years of life $[15,16]$. Previous research indicated that $5 \%$ of deaths arose in children less than five years age despite the availability of a safe and effective vaccine [17].

In this study, we noticed an increase in measles cases in March and decreased in December every year. Dry (December-May) and rainy (June-November) seasons were found to influence the effect of measles

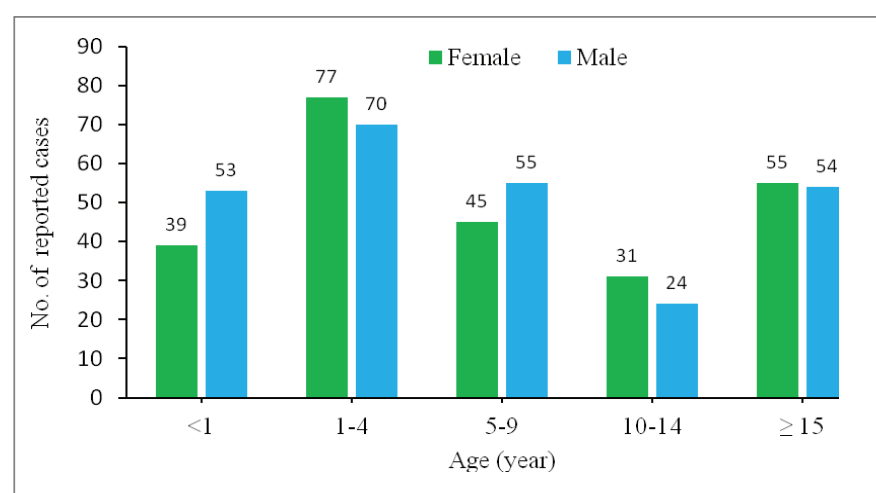

Figure 1: Gender and age differences in measles cases. 


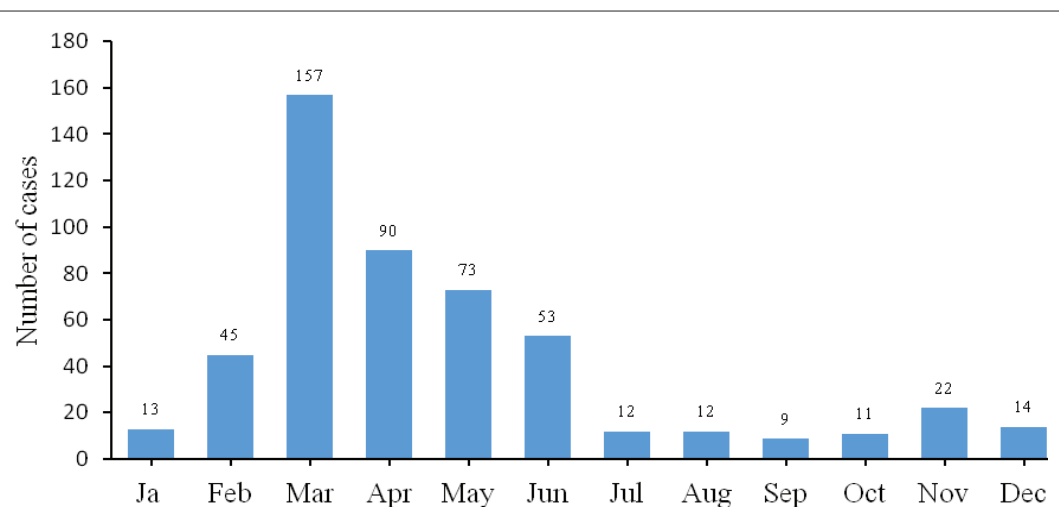

Figure 2: Seasonality of suspected measles cases in Southern Darfur State, Sudan.

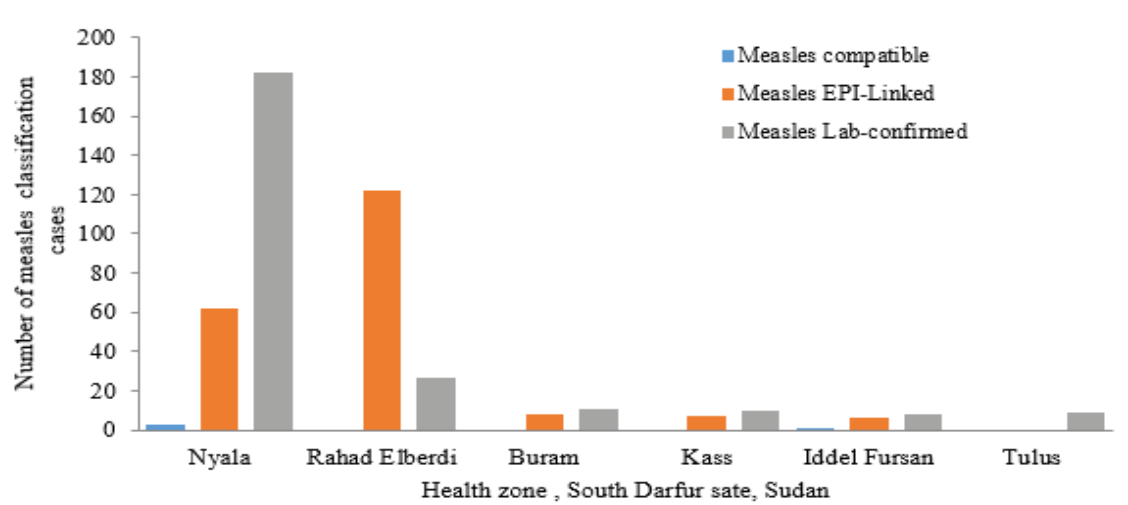

Figure 3: Measles lab-confirmed, Epi-linked and Lab-confirmed cases in different health zones.

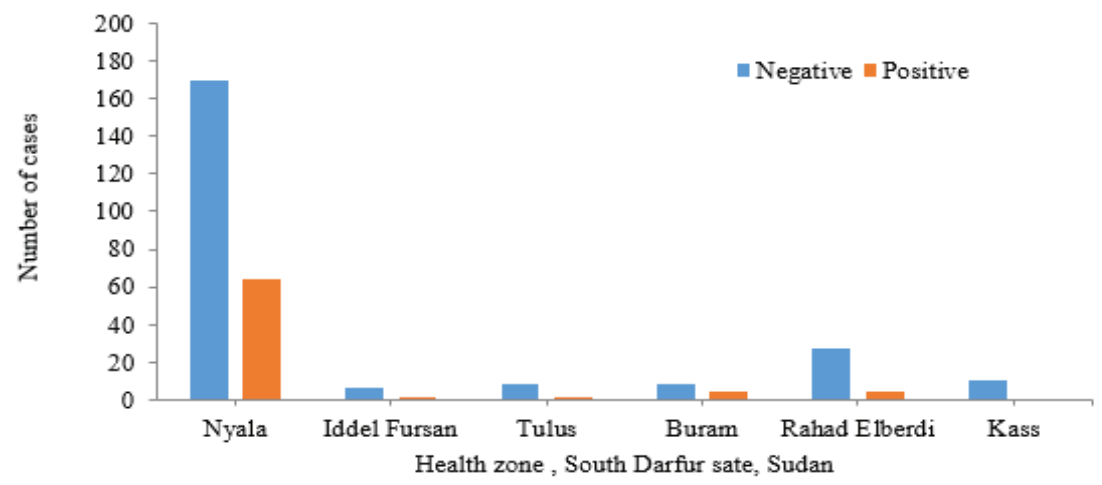

Figure 4: Measles positive and negative cases in different health zones.

virus on mortality [18]. Yang Q, et al. reported that both hot and cold temperatures decrease the incidence of measles, and low relative humidity is a risk factor for measles morbidity [19]. In temperate climates, measles typically occurs in the late winter and early spring every year, whereas, in the tropics, measles has irregular associations with rainy seasons [20].
The prevalence of positive measles IgM antibody was $43.4 \%$ in males and $56.6 \%$ in females. $48.5 \%$ of children have positive measles IgM antibody. However, Getahun $\mathrm{M}$, et al. reported 31.3\% positive measles-specific IgM in the Ethiopian population [21].

The most common clinical symptoms of measles were fever and skin rash followed by a cough, conjunctivitis and running nose. In 
Table 1: Clinical presentation of the measles cases.

\begin{tabular}{|c|c|c|c|}
\hline Characteristics & Categories & No. & (\%) \\
\hline Fever & Yes & 511 & $(100)$ \\
\hline A cough & Yes & 511 & $(100)$ \\
\hline Rash & Yes & 511 & $(100)$ \\
\hline \multirow{3}{*}{ Conjunctivitis } & Yes & 344 & $(67.3)$ \\
\hline & No & 55 & $(10.8)$ \\
\hline & Unknown & 112 & (21.9) \\
\hline \multirow{3}{*}{ Running nose } & Yes & 113 & $(22.1)$ \\
\hline & No & 322 & (63) \\
\hline & Unknown & 76 & (14.9) \\
\hline \multirow{3}{*}{ Arthritis } & Yes & 132 & $(25.8)$ \\
\hline & No & 265 & (51.9) \\
\hline & Unknown & 114 & $(22.3)$ \\
\hline \multirow{3}{*}{ lymph node } & Yes & 34 & $(6.7)$ \\
\hline & No & 281 & (55) \\
\hline & Unknown & 196 & $(38.4)$ \\
\hline \multirow{3}{*}{ Complication } & Yes sever & 128 & $(25)$ \\
\hline & Uncomplicated & 259 & (50.7) \\
\hline & Unknown & 124 & $(38.4)$ \\
\hline \multirow{3}{*}{ Measles IgM antibody } & Negative & 54 & $(10.6)$ \\
\hline & Positive & 248 & $(48.5)$ \\
\hline & Unknown & 209 & $(40.9)$ \\
\hline Travel history within the past 21 days & Yes & 511 & $(100)$ \\
\hline \multirow{2}{*}{ Vaccination status } & Vaccinated & 109 & $(21.3)$ \\
\hline & Unvaccinated & 402 & $(78.7)$ \\
\hline \multirow{3}{*}{ Vitamin A covered } & Yes & 161 & $(31.5)$ \\
\hline & No & 215 & $(42.1)$ \\
\hline & Unknown & 135 & $(26.4)$ \\
\hline \multirow{2}{*}{ Measles outcome } & Recovered & 502 & $(98.2)$ \\
\hline & Died & 9 & $(1.8)$ \\
\hline
\end{tabular}

Table 2: Gender, age and Measles IgM antibody within the different years.

\begin{tabular}{|c|c|c|c|c|c|c|c|c|}
\hline Characteristics & $\mathbf{N}$ & 2011 & 2012 & 2013 & 2014 & 2015 & $x^{2}$ & P-value \\
\hline Gender n (\%) & 511 & $147(28.8)$ & $110(21.5)$ & $116(22.7)$ & $51(10.0)$ & $87(17.0)$ & 55.68 & $<0.001$ \\
\hline Male & $222(43.4)$ & $27(5.3)$ & $64(12.5)$ & $59(11.5)$ & $30(5.9)$ & $42(8.2)$ & & \\
\hline Female & $289(56.6)$ & $120(23.5)$ & $46(9.0)$ & $57(11.2)$ & $21(4.1)$ & $45(8.8)$ & & \\
\hline Ratio & & 0.23 & 1.39 & 1.04 & 1.43 & 0.93 & & \\
\hline \multicolumn{9}{|l|}{ Age year n (\%) } \\
\hline$<1$ & $41(8.0)$ & $5(1.0)$ & $10(2.0)$ & $14(2.7)$ & $0(0.0)$ & $12(2.3)$ & 48.83 & $<0.001$ \\
\hline 4-Jan & 203 (39.7) & $60(11.7)$ & $35(6.8)$ & $50(9.8)$ & $26(5.1)$ & $32(6.3)$ & & \\
\hline 9-May & $95(18.6)$ & $28(5.5)$ & $26(5.1)$ & $23(4.5)$ & $11(2.2)$ & $7(1.4)$ & & \\
\hline 14-Oct & $57(11.2)$ & $11(2.2)$ & $12(2.3)$ & $19(3.7)$ & $7(1.4)$ & $8(1.6)$ & & \\
\hline$\geq 15$ & 115 & $43(8.4)$ & $27(5.3)$ & $10(2.0)$ & $7(1.4)$ & $28(5.5)$ & & \\
\hline \multicolumn{9}{|l|}{ Measles IgM antibody } \\
\hline Negative & $54(10.6)$ & $6(1.2)$ & $11(2.2)$ & $11(2.2)$ & $22(4.3)$ & $4(0.8)$ & 261.3 & $<0.001$ \\
\hline Positive & $248(48.5)$ & $33(6.5)$ & $27(5.3)$ & $82(16.1)$ & $27(5.3)$ & $79(15.5)$ & & \\
\hline Unknown & 208 (40.9) & $108(21.2)$ & $72(41.1)$ & $22(4.3)$ & $2(0.4)$ & $5(0.8)$ & & \\
\hline
\end{tabular}


contrast, Ibrahim SA, et al. indicated that cough and conjunctivitis were the most common manifestation followed by a running nose in Khartoum state [22]. White SJ, et al. reported that the prodromal stage occurs 10 to 12 days after exposure and is characterized by two to three days of fever, anorexia, and malaise combined with the triad of cough, conjunctivitis, and coryza. Measles induced complications affect approximately $30 \%$ of infected individuals, especially young children aged $<5$ and adults ages $\geq 20$. The most commonly reported complications are diarrhea, $8 \%$, otitis media $7 \%$, and pneumonia $6 \%$ [23].

In the present study, $21.3 \%$ of the cases were vaccinated. The previous study indicated that the timely administration of vaccines could ensure adequate protection against measles for all ages in a population [24]. Serologic and epidemiologic studies suggest that 1 -dose measles vaccine efficacy is approximately $85 \%-90 \%$ when given at nine months of age and that 2-dose effectiveness is $>99 \%$ when the second dose is given at $\geq 12$ months of age. A two-dose measles vaccination schedule might reduce not only child mortality but also improve growth [10]. This may confirm the previous studies on vaccination coverage in other parts of the world which shown socioeconomic status, insecurity, cultural diversity, community attitude towards measles and religion plays an important reason for lack of vaccine covered $[25,26]$. Furthermore, many governmental efforts were committed to the Global Measles and Rubella Elimination Strategic Plan 2012-2020. The strategies include high vaccination coverage; monitoring of disease; outbreak preparedness and response and case management; communication and community engagement; and research and development in order, to control measles among the Sudanese population [2].

The limitations of the study are that some measles cases might not be reported during the study period. Furthermore, the study was based on clinically diagnosed with measles cases and immunization history for children, but not includes other socio-demographic data. Finally, the study concludes that the increase in measles cases in Southern Darfur State from 2011 to 2015 is likely a consequence of inadequate vaccination coverage.

\section{Conclusion}

The increase in the prevalence of measles cases in Southern Darfur state is likely a consequence of the inadequate prevention and control strategies presenting in vaccination coverage and reducing the mortality rate. Therefore, performing a continues vaccination campaign towards measles control and prevention among the population will be helpful to drop measles cases and mortality among children in South Darfur.

\section{Acknowledgments}

The author acknowledges the World Health Organization and Ministry of Health Southern Darfur State, Sudan, for obtained the data for analysis.

\section{Conflict of Interest}

Authors have declared that no competing interests exist.

\section{References}

1. Medecins Sans Frontieres (2015) MSF supports the Ministry of Health to respond to measles outbreak in Sudan. Switzerland.

2. WHO (2019) Sudan Measles Situation Report Week 15 Ending on 12-04-2015. UNICEF.

3. De Swart RL, El Mubarak HS, Vos HW, Mustafa OM, Abdallah A, et al. (2001) Prevention of measles in Sudan: a prospective study on vaccination, diagnosis and epidemiology. Vaccine 19: 2254-2257.
4. El Mubarak HS (2004) Measles in Sudan: Diagnosis, Epidemiology and Humoral Immune Response. Erasmus University Rotterdam.

5. Mulholland EK, Griffiths UK, Biellik R (2012) Measles in the $21^{\text {st }}$ century. New Eng J Med 366: 1755-1757.

6. World Health Organization (2015) African Regional Guidelines for Measles and Rubella Surveillance. Geneva, Switzerland.

7. Caserta MT (2013) Measles. Merck Manual Professional. Merck Sharp \& Dohme Corp.

8. Aaby P, Samb B, Simondon F, Seck AM, Knudsen K, et al. (1995) Non-specific beneficial effect of measles immunisation: analysis of mortality studies from developing countries. BMJ 311: 481-485.

9. Manirakiza A, Kipela JM, Sosler S, Daba RM, Gouandjika-Vasilache I (2011) Seroprevalence of measles and natural rubella antibodies among children in Bangui, Central African Republic. BMC Public Health 11: 327.

10. Rasmussen $S M$, Biering-Sørensen $S$, Byberg $S$, Andersen $A$, Bjerregaard-Andersen M, et al. (2016) The effect of early measles vaccination at 4.5 months of age on growth at 9 and 24 months of age in a randomized trial in Guinea-Bissau. BMC Pediatr 16: 199.

11. Omezuruike OI, Onari JG (2017) Anti-Measles Virus (MV) IgM Antibodies in Unvaccinated Children Population in Emohua, Rivers State, Nigeria. J Health Sci 7: 1-6.

12. Musa TH, Rehab IK, Abdelkareem AA, Musa HH (2017) Epidemiology of Measles Cases in South Darfur State, Sudan, 2011-2015. Biomed Environ Sci 30: 12917-12921.

13. World Health Organization (2014) Measles. Thailand.

14. Ortega-Sanchez IR, Vijayaraghavan M, Barskey AE, Wallace GS (2014) The economic burden of sixteen measles outbreaks on United States public health departments in 2011. Vaccine 2: 1311-1317.

15. World Health Organization (2015) Sudan Measles Situation Report Week 10 Ending on 08-03-2015. Geneva, Switzerland.

16. Black FL, Berman LL, Borgono JM, Capper RA, Carvalho AA, et al. (1986) Geographic variation in infant loss of maternal measles antibody and the prevalence of rubella antibody. Am J Epidemiol 124: 442-452.

17. Getahun M, Beyene B, Ademe A, Teshome B, Tefera M, et al. (2016) Epidemiology of laboratory-confirmed measles virus cases in Amhara Regional State of Ethiopia, 2004-2014. BMC Infect Dis 16: 113.

18. Bryce J, Boschi-Pinto C, Shibuya K, Black RE, WHO Child Health Epidemiology Reference Group (2005) WHO Child Health Epidemiology Reference Group. WHO estimates of the causes of death in children. Lancet 365: 1147-1152.

19. Yang Q, Fu C, Wang N, Dong Z, Hu W, et al. (2014) The effects of weather conditions on measles incidence in Guangzhou, Southern China. Hum Vaccin Immunother 10: 1104-1110.

20. Aaby P, Martins CL, Garly ML, Balé C, Andersen A, et al. (2010) Nonspecific effects of standard measles vaccine at 4.5 and 9 months of age on childhood mortality: randomized controlled trial. BMJ 341: c6495.

21. Getahun M, Beyene B, Ademe A, Teshome B, Tefera M, et al. (2017) Epidemiology of laboratory-confirmed measles virus cases in the southern nations of Ethiopia, 2007-2014. BMC Infect Dis 17: 87.

22. Ibrahim SA, Mustafa OM, Mukhtar MM, Saleh EA, El Mubarak HS, et al. (2002) Measles in suburban Khartoum: an epidemiological and clinical study. Trop Med Int Health 7: 442-449. 
23. White SJ, Boldt KL, Holditch SJ, Poland GA, Jacobson RM (2012) Measles, mumps, and rubella. Clin Obst Gyn 55: 550-559.

24. Moss WJ, Griffin DE (2012) Measles. Lancet 379: 153-164.

25. Wagner AL, Zhang Y, Montgomery JP, Ding Y, Carlson BF, et al. (2014) Timely measles vaccination in Tianjin, China: a cross-sectional study of immunization records and mothers. BMC Public Health 14: 888.

26. Luhm KR, Cardoso MR, Waldman EA (2011) Vaccination coverage among children under two years of age based on electronic immunization registry in Southern Brazil. Revista de saude publica 45: 90-98. 